\title{
Eccentricity Fault Diagnosis in BLDC motor using Finite Element and Frequency Research
}

\author{
Gunjan Sardana, Neelam Turk, Satvir Deswal
}

\begin{abstract}
The present article examines how rotor, stator and eccentricity faults can be identified in a Brushless DC (BLDC) motor. For a defective BLDCM, a novel finite-element analysis (FEA) index is implemented for non-invasive detection of such faults. The selected index was the elements for amplitude/frequency modulation units with a specific pattern of frequency obtained from the stator current spectrum. The application of this index enables the incidence and type and the proportion of eccentricity to be accurately determined. A finite-element analysis (FEA) method that takes into consideration all the structural and physical features of the motor elements, nonuniform permanent-magnet (PM) features as well as nonuniform air gap permeance, is used to model the BLDC eccentricities. In an attempt to be processed accurately, this model employs tools such as FFT, STFT, Wigner-Ville, Choi Williams analysis and Gabor Transforms to the expected indicators. The suggested index is validated by comparing the simulation and experimentation outcomes of both healthy and faulty machines.
\end{abstract}

Index terms: Dynamic eccentricity, BLDC motor, Fault-detection, FFT, SIFT, Wigner-Ville analysis.

\section{INTRODUCTION}

Brushless DC (BLDC) motors also known as "Permanent-magnet synchronous motors (PMSM)," most commonly used in industries and transportation due to their high-performance outputs like torque, high volume ratio and improved dynamic performances compared as to brushed DC motors and induction motors. The brushless DC motors comprises of an electrical regulated switching system, a rotor which contains a range of PMs and a armature that is static and not mechanically operated as in brushed DC (BDC) motors [1]. The BLDC motors along with the stator and rotor can be seen in Figure 1. Fault detection at early stages, to avoid any breakdown of faulty component and other components in BLDC motor is requisite to boost its efficiency, extend its life and reduce heavy costs.

\section{BLDC MOTOR FUNCTIONING AND FAULTS}

\subsection{Functioning of BLDC motor}

Coils are configured in a static magnetic field and electrical current passes through these coils. This flow of current produces electromagnetic fields within the coils generating a rotating force. The characteristic features of BLDC motor are:

Revised Version Manuscript Received on 16 September, 2019.

Gunjan Sardana Electronics Department, YMCAUST, Faridabad, India, E-mail: gunjansardana83new@gmail.com India

Dr. Neelam Turk, Electronics Department, YMCAUST, Faridabad, India a. Rotor is a permanent magnet

b. Coils are not located on the rotor

c. Even at peak rotating force (torque), Brushless DC motors can operate constantly

d. In this coil are not rotated, however remain fixed onto the stator instead.

e. Since the coils are not moving, no commutator or brushes are required

The rotatory motion is accomplished by regulating the electromagnetic fields produced by the rotor coils, while the magnetic field produced by the PM stays unchanged.

Moreover, small BLDC motors can deliver considerable power as compared to BDC motors.

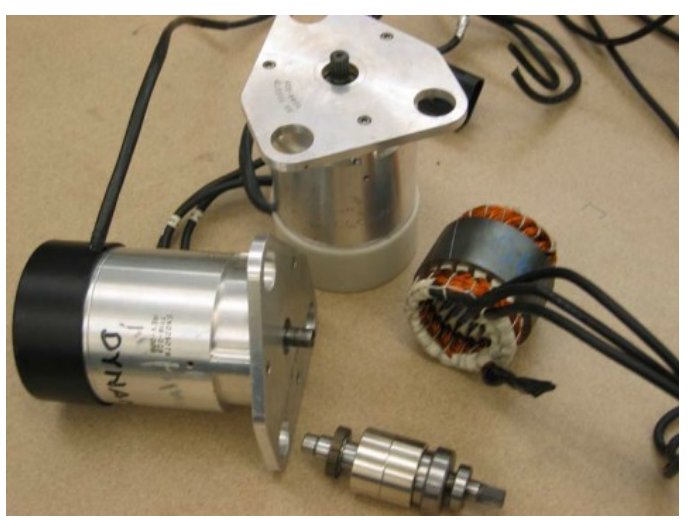

Fig 1. BLDC motors

In comparison to BDC motors or induction motors, the BLDC motors are very advantageous. Some are high dynamic reactions, speed/torque values, higher effectiveness, extended operational life, silent operations and expanded speed capabilities.

Figure 2 represents the fundamental block diagram of BLDC motor. The BLDC motors consists of 4 major components PMSM, energy converters, control algorithms and HAL sensors. The power transducer converts and supplies electricity to the PMSM, which in turn transforms electricity into mechanical energy.

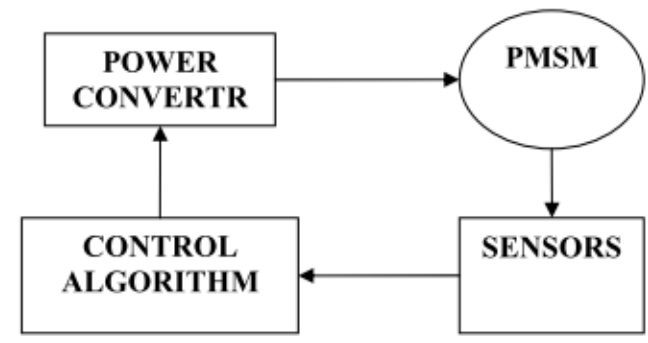

Fig.2 BLDC motor work concept diagram

Furthermore, the proportion 
of thrust compared to the motor's small volume is greater, which makes it effective when weight and space are important used by applications wherein the high-performance is vital [2]. Consequently, a greater significance is thus, given to the fault detection and inspection of the BLDC motor conditions.

\subsection{BLDC Motor Faults}

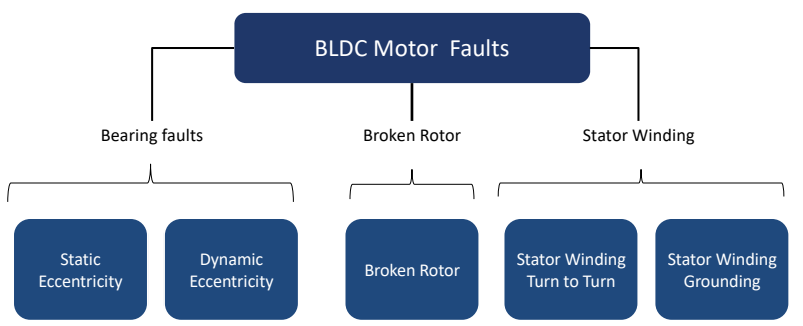

Fig 3. BLDC Motor Faults

Potential defects can be divided between rotor faults, bearing defects, stator defects, inverter defects, within a BLDC motor (see Figure 3). Generally, the faults of 4 kinds, such as rotor defects $(10 \%)$, stator faults $(35 \%)$, bearing faults $(42 \%)$, and various other motor related faults $(13 \%)$. The stator defects could also be classified in the subsequent classifications (Table I):

Table I: Root causes of stator faults.

\begin{tabular}{|l|l|}
\hline Root Causes for Stator Faults & Percentage (\%) \\
\hline Bracing & $3 \%$ \\
\hline Ground Insulation & $21 \%$ \\
\hline Cable & $1 \%$ \\
\hline Wedges & $1 \%$ \\
\hline Turn Insulation & $4 \%$ \\
\hline Frame & $1 \%$ \\
\hline Other & $3 \%$ \\
\hline
\end{tabular}

\subsubsection{Root Causes of Stator Winding Fault Failures}

The winding insulation failure or breakdowns are the most often happening stator faults. It generally happens in the areas of the stator brackets wherein the final winding enters. It is triggered due to pressure of high electrical voltages, electro-dynamic forces generated by coil currents, multi-heating/cooling cycle, internally and externally induced mechanical vibrations and thermal aging. This failure of winding insulations can contribute to further failures which ultimately lead in ground short-circuits, resulting in well known "grounded stator windings."

\subsubsection{Thermal Stresses}

The overloading and aging of windings, attributed to continuous operations of motor results in thermal faults. As per the study by Bhowmik et al., [3], it is observed that the life of insulation is directly proportional to the rise of temperature, which further leads to the vulnerability of overall windings.

$$
L \alpha \Delta T
$$

where, $\mathrm{L}=$ Loss of Insulation

$\mathrm{T}=$ Rise in Temperature

\subsubsection{Rotor Faults}

Eccentricities, demagnetization of PM, damaged hall detectors, broken rotor magnets represent potential rotor failures observed in BLDC motors. All the mentioned rotor defects consequently trigger generation of noises and considerations. BLDC motors therefore, are most frequently

vibrations. Additionally, they also trigger dynamic issues with the torque pulsations of the motor.

A significant fault, commonly observed in BLDC machines, is disruption of an air-gap flux (see Figure 4 and 5), which arises from irregularity of attached PMs [4]. Some PMs (Nd-Fe-B) are subjected to corrosion and considered to erode and may cause motor collapse [5].

Due to demagnetization or partial magnetization, flux disruptions also can be induced. There are multiple reasons for demagnetization of PMs. These disruptions in the flow of flux may result in unequaled magnetic traction among both the rotor and the stator leading to greater resistances in the roller coils. This could ultimately contribute to damages to the bearings.

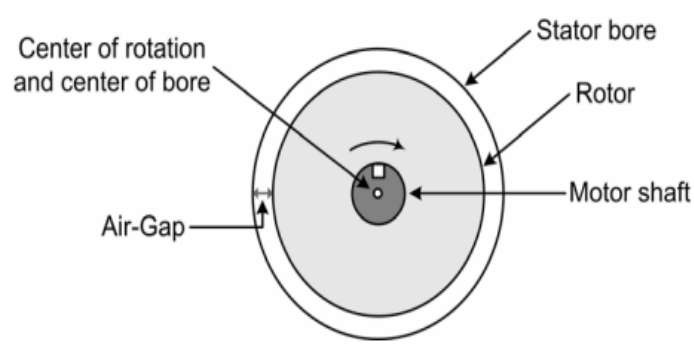

Fig 4 .Non-eccentricity air-gap in a healthy electric motor.

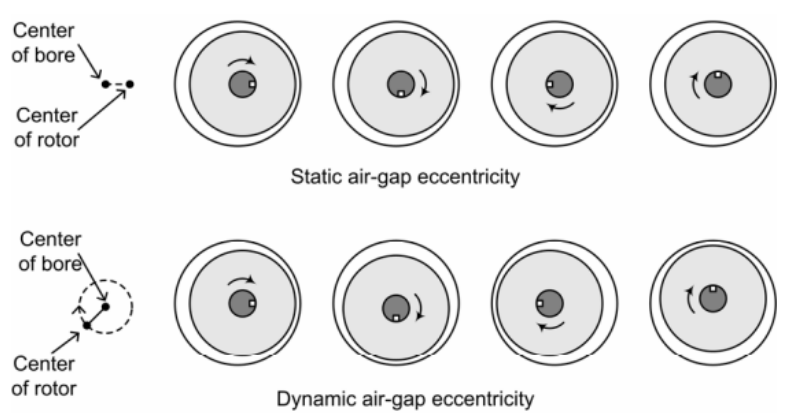

Fig 5. Types of air-gap eccentricity faults (static eccentricity (SE) and dynamic eccentricity (DE) in faulty motors).

Eccentricity faults have been observed to increase magnetic-flux density, unbalance in magnetic pull (UMP), density of the radial power, and harmonic deflections in density of radial force, which are mostly due to static eccentricity (SE) defects.

\section{III.PREVIOUS WORKS}

Various authors showed that rotor faults in constantly running BLDC motors influence some frequency response harmonic elements in the motor's current-stator system. The flux amplitude of such harmonic elements could be monitored for detecting certain rotor failures [ 6-7]. The stator current's frequency spectrum is calculated using a Fast-Fourier (FFT) transform within the "Motor Current Signature Analysis (MCSA)" [8]. 
In past few years, several papers were released concerning the production of noises and vibrations in PMSM motors [9-11]. Though, the vibro-acoustic quality of the faulty motors in association with defects and demagnetizations have not been much investigated [12].

In [13], a radial force, UMP, cogging torque and electric power torque were analyzed in good and defective BLDC motors related to eccentricity issues. UMP, radial strength, cogging torque and torque ripples have been observed to expand owing to eccentricities.

In [14] the BLDC motor under eccentricity faults were calculated statistically in stator currents, taking into consideration air-gap flux density and cogging torque as eccentricity faults. The variable frequency and amplitude of the cogging torque have been shown to increase under eccentricity.

\section{METHODOLOGY}

In order to evaluate eccentricity defects, an analytical strategy relying on a $2 \mathrm{D}$ magnetic field principle has been applied in polar coordinates which neglects slotting impact. Neglecting stator slots can be recognized for a number of impacts upon the motor's efficiency calculations. A disturbance technique was used to compute the flux amplitude and density distribution along the top of the stator. Nearly all credible techniques of failure detection are dependent on comprehensive actual parameters as well as circumstances. The very first stage in the fault detection method is a accurate and relevant modeling. The comprehensive model design is taken into consideration for detailed models depending on magnetic field calculation to produce extremely precise outputs. Figure 6 represents Proposed Experiment Methodology.

\section{Tool Used:}

Motor Design: Ansys RmXprt

Simulation of 2D motor: Ansys Maxwell

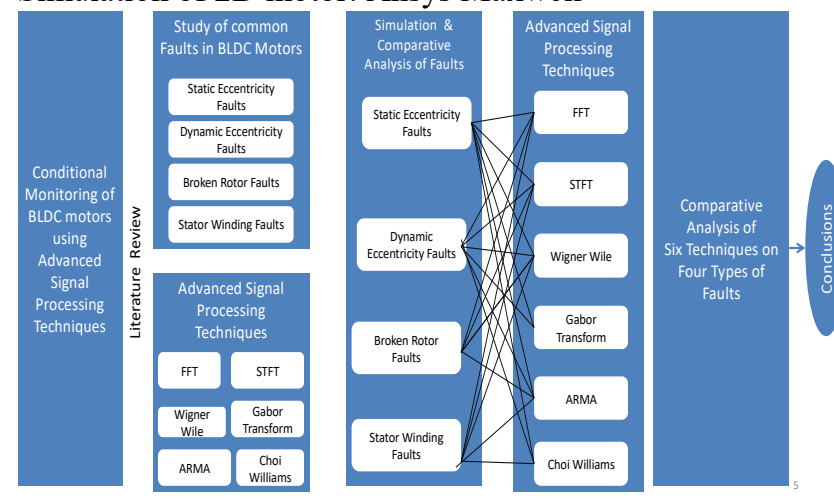

Figure 6: Proposed Experiment Methodology

\subsection{Research Objectives}

To develop the condition monitoring schemes for operation of BLDC motor.

To identify and classify the faults of BLDC motor through literature survey and experiments.

To simulate the operation of BLDC motor for diagnosis of different faults.

To develop some advanced fault detection methods to detect the possible faults of BLDC motors, resulting in reduction of the cost of continuous monitoring of operation of BLDC motor.

\subsection{Methods for Fault Detection}

\section{Dynamic Eccentricity Faults}

A dynamic eccentricity (DE) generates a magnet unbalance pull (UMP), which runs at the velocity of the motor rotations, acting directly on the rotor. UMP can be identified in dynamic eccentricities or with the current tracking.

\section{FFT Analysis}

The FFT spectrum can be acquired by means of an integrated Fast Fourier Transformation (FFT) applied on the faulty signal,

$$
f_{d c}=f_{e} \pm k \frac{f_{e}}{P / 2}
$$

where fe is the fundamental frequency, fde is the dynamic eccentricity (DE) frequency, $\mathrm{k}$ is any integer and $\mathrm{P}$ is number of poles.

\section{1) Reason for FFT Analysis}

For various failures in motors, fault frequency bands in the motor spectrum are distinctive. Moreover, the future is bright for electrical monitoring since it is cost-effective and safe.

\section{2) Short-Time Fourier transform (STFT) Analysis}

To propose a windowed Fourier ridge algorithm for the identification of BLDC motor's rotor faults operating under continuous non-stationarity mode. It was assumed that the current in the stator incorporates distinctive fault frequency modules for rotor defect analysis.

$$
S f(t, \xi)=\int_{-\infty}^{+\infty} s(\tau) g(\tau-t) e^{-t \xi \tau} d \tau
$$

where, $\mathrm{t}$ is the instant time, $\mathrm{g}(\tau)$ is an actual and symmetrical window interpreted by $t, \xi$ is the frequency, whereas, $\tau$ indicates the "running time."

\section{3) Choi-Williams Distribution}

The Choi-Williams distribution (CWD) model is a cross-term repressing exponential linear matrix, in which the value of sigma governs the balance among cross-term removal and amplitude resolutions in frequency.

\section{4) Gabor Transform}

The Gabor transform has been used to evaluate the frequency and stage composition of sine wave parts of a wave signal, since it transforms with changing time.

Gaussian function is a window function; thus, the outcome is converted to obtain the time-frequency assessment 
with a Fourier transform.

With the window function, there seems to be a greater weight for the message close to the moment of analysis.

The below equation defines the Gabor transformation of the message $\mathrm{x}(\mathrm{t})$ :

$$
G_{x}(t, \omega)=\int_{-\infty}^{+\infty} x(t) e^{-\pi(t-\tau)} e^{-j \omega t} d t
$$

\section{5) Wigner-Ville Analysis}

The allocation of Wigner and its multiple combinations is a method for analyzing defects commonly utilized for the fault detection in mechanical devices. Classification of response $\mathrm{s}(\mathrm{t})$ from Wigner-Ville distribution can be distributed as:

$$
W(t, \omega)=\frac{1}{2 \pi} \int_{-\infty}^{+\infty} e^{-j \omega \tau} s^{*}\left(t-\frac{\tau}{2}\right) s\left(t+\frac{\tau}{2}\right) d \tau
$$

where $\omega$ is the angular frequency, $\mathrm{s}^{*}$ is the conjugate of $\mathrm{s}(\mathrm{t})$, $\mathrm{t}$ is the static time of interest, $\tau$ is the "running time," and $\mathrm{f}$ is the instantaneous frequency.

Table 2: BLDC experimental setup (Rotor data)

\begin{tabular}{|l|l|} 
ROTOR DATA & 1.5 \\
\hline Minimum Air Gap (mm): & 0.912291 \\
\hline \hline Electrical Pole Embracing: & XG196/96 \\
\hline Magnet Type: & 34.1975 \\
\hline Width of Magnet (mm): & 3.25 \\
\hline Maximum Magnet Thickness (mm): & No \\
\hline Magnetic Shaft: & 65 \\
\hline \hline Rotor Length (mm): & 1 \\
\hline Rotor Type: & 0.95 \\
\hline Stacking Factor of Iron Core: & M19_24G \\
\hline Type of Steel: & 24 \\
\hline Inner Diameter (mm): & 36 \\
\hline Polar Arc Radius (mm): & 0.95 \\
\hline \hline Mechanical Pole Embracing: & \\
\hline
\end{tabular}

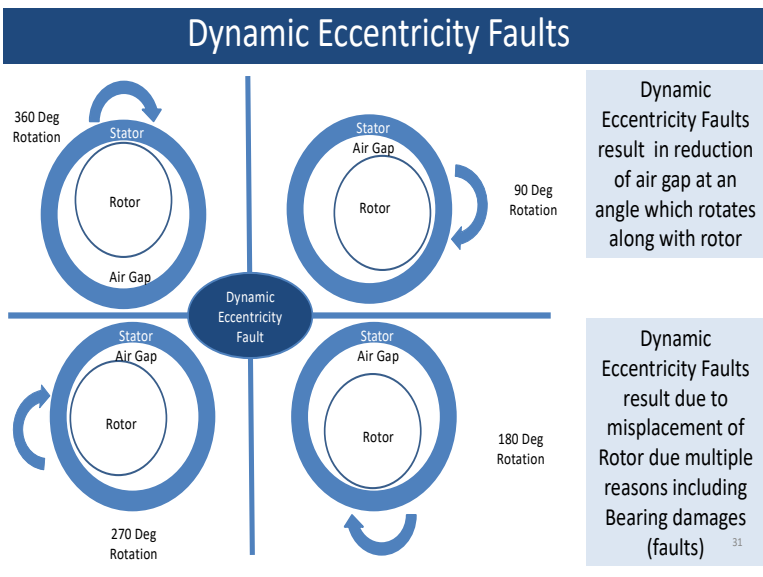

Fig 7 : Analyzing dynamic eccentricity (DE) faults

\section{SIMULATION RESULTS}

Simulations were run for determining the faults. The simulation of 2D was performed on Ansys Maxwell software. A comparison was done among the healthy BLDC motor and faulty motors. The results were then compared to derive the conclusion of the study.
The frequencies of faults for a six-pole BLDC motor are much like the dynamic eccentricities (DE), namely $1 / 3 \mathrm{rd}$, 2/3rd, 4/3rd, and 5/3rd of the central frequency. Experimental results are provided in Tables 4 and 5 for the light (30\% load) and full load cases at an operating speed of $1800 \mathrm{rpm}$. The measurement accuracy is again about $+10 \%$.
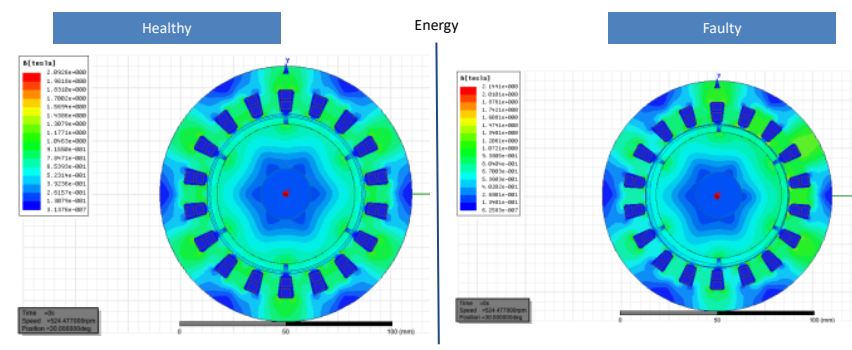

Fig 8 Comparing healthy and faulty BLDC motors
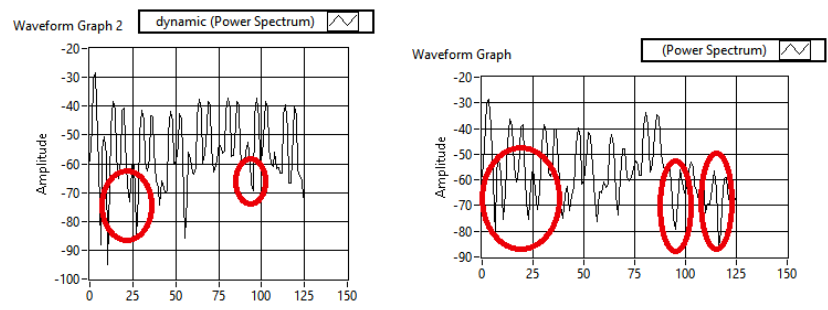

Fig 9 .Analysis of Dynamic Eccentricity (DE) power spectrum

Table 4: Qualitative analysis of healthy and faulty BLDCM

\begin{tabular}{|l|l|}
\hline Amplitude of Healthy BLDC Moor & -57.0842525 \\
\hline \hline Faulty Motor with Dynamic Eccentricity Faults & -55.234895 \\
\hline Percentage Variation & $3.348 \%$ \\
\hline
\end{tabular}
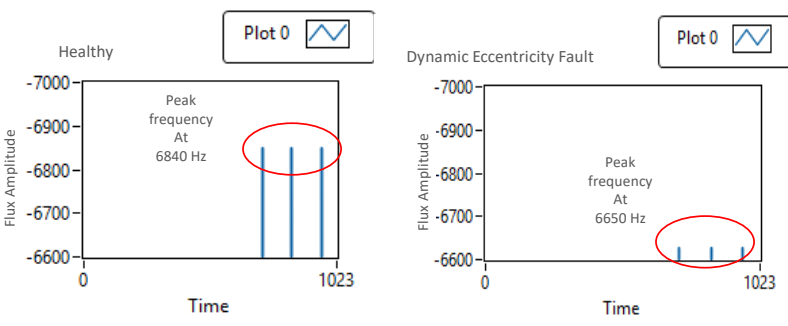

Fig 10. Comparative Analysis of Flux Linkage

A difference of 190 units in the flux amplitude was observed between healthy and faulty motors (Figure 10).
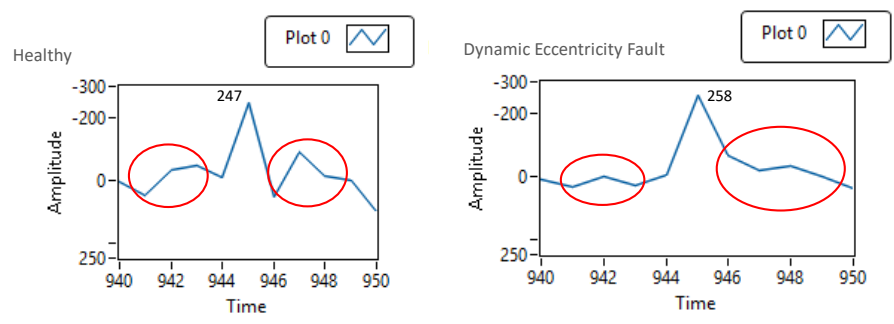

Fig 11. FFT Analysis of Second Quadrant (Second peak)

Published By: 


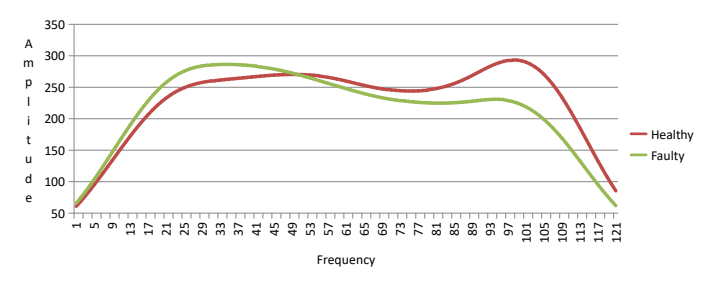

Fig 12: Graph of STFT Analysis
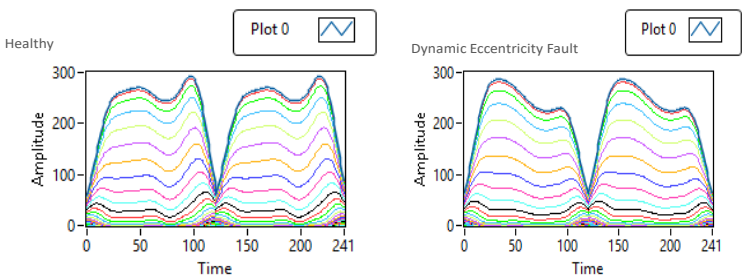

Fig 13: STFT Analysis (Flux linkage)
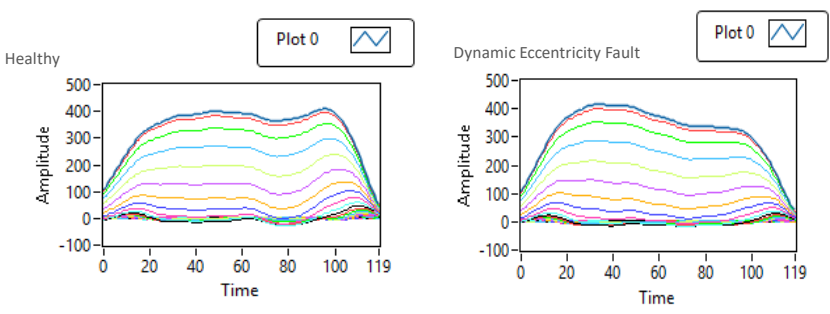

Fig 14. Gabor Analysis of FTP

Table 5: Comparative parameters of Gabor Analysis of FTP

\begin{tabular}{|l||l|l|}
\hline Average & 334.8604667 & 317.65985 \\
\hline Peak & 409.415 & 415.79 \\
\hline $\begin{array}{l}\text { \%age Variation with Respect to He } \\
\text { althy motor in peak amplitude }\end{array}$ & $-1.56 \%$ & \\
\hline $\begin{array}{l}\text { \%age Variation with Respect to He } \\
\text { althy motor in Average amplitude }\end{array}$ & $-5.14 \%$ & \\
\hline
\end{tabular}
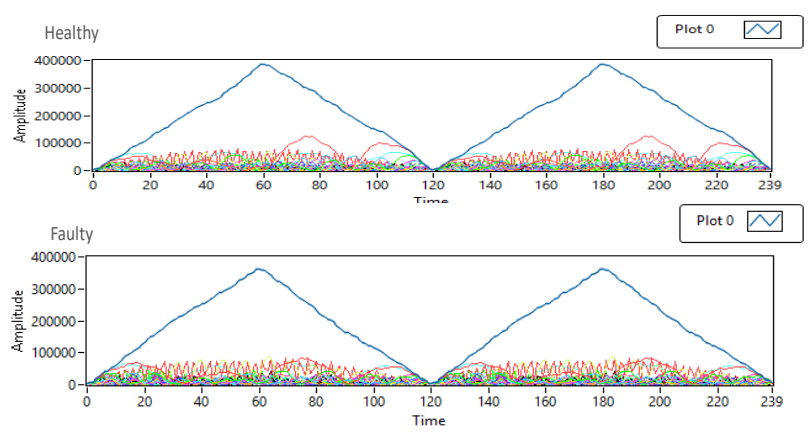

Fig 15: Comparison of Wigner-Ville Analysis

Table 6: Comparative parameters of Wigner-Ville analysis

\begin{tabular}{|l|l|l|}
\hline Parameter & Healthy & Faulty \\
\hline Average Amplitude & 196318.9 & 183807.2 \\
\hline Peak Amplitude & 386911.0 & 362286.0 \\
\hline $\begin{array}{l}\text { Percentage Variation of Average Amplit } \\
\text { ude }\end{array}$ & $-6.3732 \%$ & \\
\hline Percentage Variation of Peak Amplitude & $-6.3645 \%$ \\
\hline
\end{tabular}

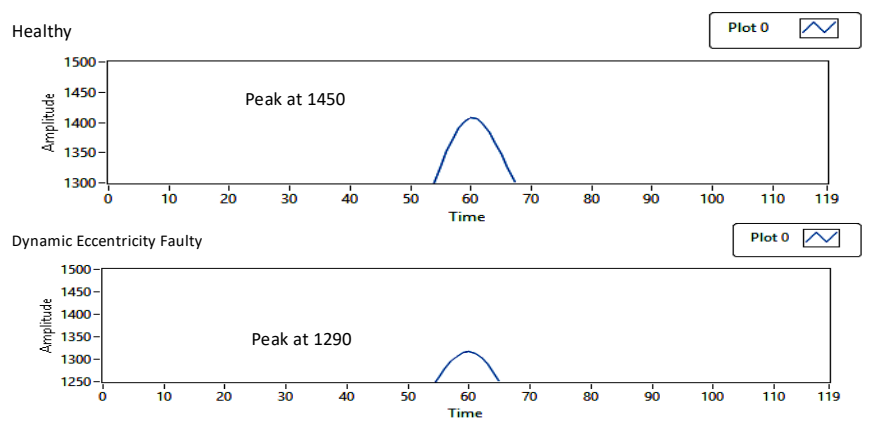

Fig 16: Comparison of Choi Williams Analysis

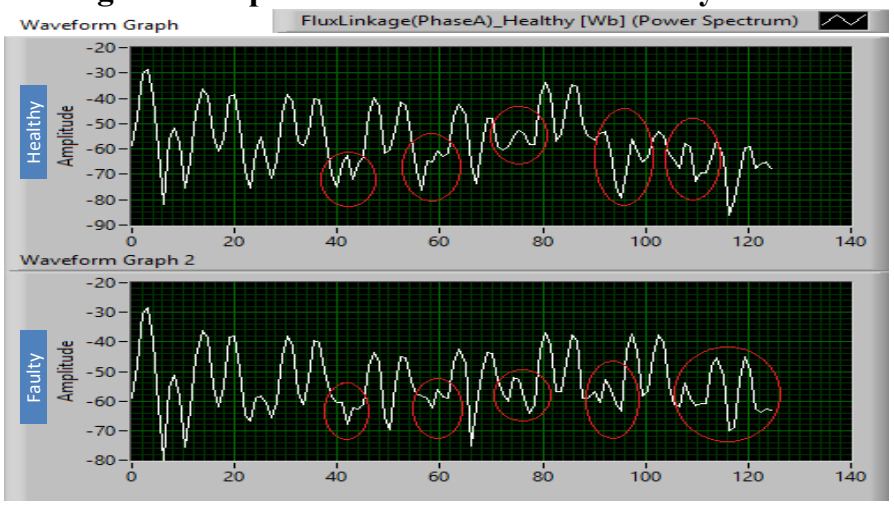

Figure 17: Comparison of Power Spectrum Analysis (Flux density)

\section{CONCLUSION}

This paper reveals how eccentricity faults like SE, DE can be identified in BLDC motors. The detection of eccentricity and the identification of its class and extent have been based on a new FEA frequency pattern. An FFT, Wigner-Ville, Choi Williams analysis and Gabor transform model of the defective BLDC motor with SE, DE has been evaluated. The current spectrum of stator was measured by FFT while the flux amplitude was implemented as a true index for this model. The suggested indicator was reliable against load changes and thus no machine loads for the precise detection of faults needs to be specified. This approach therefore, is much more effective than other indicators used to diagnose faulty eccentricity in BLDC machines. However, a spectrum current correlation among healthy and defective BLDC motor due to open circuit and eccentricity, short-circuits and demagnetization indicates that such sideband elements are generated only under eccentricity. Distinguishing is thus feasible with this coefficient among eccentricity and several other defects. Regression studies were carried out to analyze the efficiency of the implemented method. The simulated current was supplemented with white Gaussian noise and regarding the variance in flux amplitude and vibration, the

validity of the specified method was evaluated. This method therefore, can be employed for creating an extremely precise fault detection scheme for BLDC motors, which may allow an evaluation of eccentricity as well as other form of faults at an accepted error frequency.

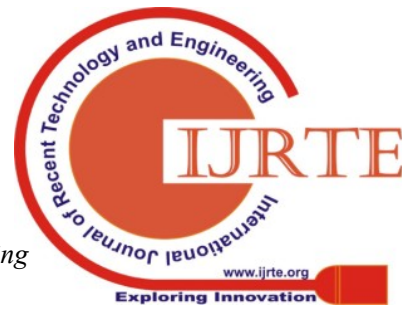




\section{REFERENCES}

1. Yedamale P. Brushless DC (BLDC) motor fundamentals. Microchip Technology Inc. 2003 Jul 28;20:3-15.

2. Villani M, Tursini M, Fabri G, Castellini L. High reliability permanent magnet brushless motor drive for aircraft application. IEEE transactions on industrial electronics. 2011 Jun 27;59(5):2073-81.

3. Rajagopalan S, Aller JM, Restrepo JA, Habetler TG, Harley RG. Detection of rotor faults in brushless DC motors operating under nonstationary conditions. IEEE Transactions on Industry Applications. 2006 Nov 13;42(6):1464-77.

4. Bhowmik PS, Pradhan S, Prakash M. Fault diagnostic and monitoring methods of induction motor: a review. International Journal of Applied Control, Electrical and Electronics Engineering (IJACEEE). 2013 May 18;1(1):1-8.

5. Wang X, Li Q, Wang S, Li Q. Analytical calculation of air-gap magnetic field distribution and instantaneous characteristics of brushless DC motors. IEEE Transactions on Energy Conversion. 2003 Aug 26;18(3):424-32.

6. West JG. DC, induction, reluctance and PM motors for electric vehicles. Power Engineering Journal. 1994 Apr 1;8(2):77-88.

7. Rajagopalan S. Detection of Rotor and Load Faults in BLDC Motors Operating Under Stationary and Non-Stationary Conditions (Doctoral dissertation, Georgia Institute of Technology),

8. Nandi S, Ilamparithi TC, Lee SB, Hyun D. Detection of eccentricity faults in induction machines based on nameplate parameters. IEEE Transactions on Industrial Electronics. 2010 Jul 1;58(5):1673-83.

9. Ebrahimi BM, Faiz J. Magnetic field and vibration monitoring in permanent magnet synchronous motors under eccentricity fault. IET electric power applications. 2012 Jan 1;6(1):35-45.

10. Boucherit A, Srairi S, Djerdir A, Miraoui A. Analytical and numerical modelling of demagnetization phenomenon in a permanent magnet motor. In16th International Conference on Electrical Machines, ICEM 2004 Sep (pp. 127-128).,

11. Lee HJ, Chung SU, Hwang SM. Noise source identification of a BLDC motor. Journal of Mechanical Science and Technology. 2008 Apr 1;22(4):708.

12. Ko HS, Kim KJ. Characterization of noise and vibration sources in interior permanent-magnet brushless DC motors. IEEE Transactions on Magnetics. 2004 Nov 8;40(6):3482-9.

13. Boucherit A, Srairi S, Djerdir A, Miraoui A. Analytical and numerical modelling of demagnetization phenomenon in a permanent magnet motor. In16th International Conference on Electrical Machines, ICEM 2004 Sep (pp. 127-128).

14. Yoon T. Magnetically induced vibration in a permanent-magnet brushless DC motor with symmetric pole-slot configuration. IEEE Transactions on Magnetics. 2005 Jun 6;41(6):2173-9.

15. Zhao W, Chau KT, Cheng M, Ji J, Zhu X. Remedial brushless AC operation of fault-tolerant doubly salient permanent-magnet motor drives. IEEE Transactions on Industrial Electronics. 2009 Oct 9;57(6):2134-41. 